\title{
Analysis of the Generating and Influencing Factors of Vertical Cracking in Abutments during Construction
}

\author{
Xingwei Xue $\mathbb{D}$, ${ }^{1,2}$ Junlong Zhou $\mathbb{D}^{1},{ }^{1}$ Xudong Hua $\mathbb{D}^{1},{ }^{1}$ and Hongnan Li $\mathbb{C}^{1}$ \\ ${ }^{1}$ School of Traffic Engineering, Shenyang Jianzhu University, Shenyang, Liaoning 110168, China \\ ${ }^{2}$ MOE Key Lab of Disaster Forecast and Control in Engineering, Jinan University, Guangzhou, Guangdong 510618, China
}

Correspondence should be addressed to Xingwei Xue; gdansys@163.com

Received 21 October 2017; Revised 4 January 2018; Accepted 10 January 2018; Published 19 March 2018

Academic Editor: Enzo Martinelli

Copyright (c) 2018 Xingwei Xue et al. This is an open access article distributed under the Creative Commons Attribution License, which permits unrestricted use, distribution, and reproduction in any medium, provided the original work is properly cited.

In order to analyze the causes of cracking in abutments subject to concrete shrinkage and temperature variation during the construction process and to determine factors affecting the mechanical properties of the abutment, nonlinear calculations capturing abutment behavior are conducted with Midas/FEA software. Using these calculations, the cracking mechanism is identified, and the influence of the evaluated factors is analyzed. It is concluded that the deformation between the pile cap and abutment backwall as constrained by a pile foundation when subjected to concrete shrinkage and temperature changes is the basic cause of abutment cracks during construction; these cracks form over the piles and develop upward. For a given reinforcement ratio, the distribution of horizontal crack-control steel using small, closely spaced bars is more beneficial. When pile-bearing capacity meets the standard, the width of the generated cracks tends to decrease with the decrease in the diameter of the piles. The existence of a postcast strip in the abutment backwall also contributes to the decrease in the depth of the crack. Finally, the impact of age difference between the pile cap concrete and abutment backwall concrete on cracking is inconsequential.

\section{Introduction}

The typical bridge abutment is composed of a pile foundation, pile cap, abutment cap and backwall (including bracket), and wingwall. The construction of an abutment must be conducted in a sequence: the pile foundation is installed first, then the pile cap, and then the abutment cap and backwall. Therefore, there are significant age differences between members that constitute the abutment, and vertical cracks may appear in the backwall above the piles owing to this age difference, shrinkage forces, or temperature forces created, in part, by the generation of hydration heat during concrete curing. Therefore, strength monitoring is vital to ensure the safe construction of an abutment and to determine its readiness for service after it has been cast.

To enable the effective monitoring of cast concrete, Munuswamy and Sivakumar [1] analyzed the force conditions in concrete under abutment restraint conditions when subject to the time-dependent effects of creep and shrinkage, relaxation of prestressing steel, and temperature gradient. To accomplish this, taking the abutment-pile-soil system into account (using discrete spring stiffness to describe the translational and rotational degrees of freedom), concrete cracking was initiated by the application of lateral load, and the behavior of the piles supporting the abutment was evaluated and presented in terms of lateral deflection, bending moment, shear force, and stress along the pile depth.

Wang and Zhou [2] highlighted the cracking associated with tall abutments as a critical issue in highway construction. Four U-shaped abutment models were built using clay bricks to provide a contrast analysis of failure mechanism: three models with different arrangements of structural stiffeners and one model of a common abutment. These abutment models were loaded by filling them with soil and applying an external vertical load on the surface of the soil. It was found that the stiffeners had an obvious effect on the cracking of the abutment model, resulting in higher cracking loads compared to that of the common abutment.

To evaluate the behavior of different components of a bridge structure under the effect of temperature variation, 
Shoukry et al. [3] developed a detailed instrumentation system for a 3-span continuous steel girder bridge with integral abutments. The instrumentation plan was developed to provide continuous monitoring of the triaxial state of strain, temperature gradient, crack opening, and relative movement between substructure elements. The results indicate that the motion of the substructure owing to the expansion or contraction of the bridge superstructure is partially restrained, generating thermal stresses in the girders and the deck that are not currently accounted for in bridge design.

Abutment behavior was modeled by Yu et al. [4], who performed a finite element analysis of an abutment on the Xiangshan Harbor Highway Bridge in Ningbo. In order to understand the effects of the hydration heat of mass concrete on surface cracking in the early stage of casting, the effects of the four parameters, concreting temperature, environmental temperature, material of the insulating layer, and constraint conditions on surface stress, were analyzed. The results reveal that tensile stress on the surface of the concrete is proportional to the casting temperature while inversely proportional to the environmental temperature. Heat preservation was found to reduce the surface tensile stress more efficiently in the center than at the edge of the abutment, and increasing the stiffness of the concrete formwork was found to effectively prevent cracks.

Flaga et al. [5] presented two approaches to investigating thermal shrinkage stresses and cracking risk in early-age concrete structures: a simplified engineering method and a 3D numerical model. The results of these stress analyses were compared and validated against the behavior of a real abutment upon which cracking had been observed in the early phases of construction.

Although the researchers in [1-5], as well as many others [6-10], have studied and analyzed the stress conditions of bridge abutments under the impact of temperature, live load, and creep and shrinkage, further efforts must be made to investigate the stress mechanism of abutment cracking during construction as a result of hydration heat, the cooling effect from changes in atmospheric temperature, the shrinkage difference between the concrete of the pile cap and the abutment body, and constraints applied by the pile foundations. Notably, few studies have analyzed other factors influencing the formation of abutment cracks, such as the arrangement of lateral anticrack reinforcement, the rigidity of the pile foundation, the difference in the age of the concrete of the pile cap and the abutment body, and the presence of a postcast backwall strip.

In order to determine the effects of these factors, this paper employs the 3D finite element analysis software package Midas/FEA to analyze a 3D finite element nonlinear model of the flyover located at Cuixiang Road, Dongguan, to determine the stress mechanism behind abutment cracking observed during construction. The model was also used to analyze the influence of different factors, such as the lateral anticracking reinforcement, the pile foundation rigidity, the difference in the age of the pile cap and the abutment backwall concrete, and the inclusion of a postcast strip on the stress in the abutment. This information was then used to provide suggestions for preventing and controlling the formation of vertical cracks on bridge abutments during construction.

\section{Materials and Methods}

\subsection{Subject Abutment}

2.1.1. Overview of Abutment. The flyover at Cuixiang Road, Dongguan City of China, consists of a $30 \mathrm{~m}$ long continuous prestressed concrete box girder bridge with $8 \mathrm{~m}$ long approach slabs and D80 expansion joints on both ends. The $19 \mathrm{~m}$ wide bridge is designed for Class-I highway loads and is equipped with $19 \mathrm{~m}$ wide straight abutments, as shown in Figure 1.

Under the pile cap, there are eight D130 friction-type piles in two rows. The pile cap is $1.5 \mathrm{~m}$ deep, $6.3 \mathrm{~m}$ in the longitudinal direction of the bridge, and $19.0 \mathrm{~m}$ in the transverse direction of the bridge. The abutment backwall is $100 \mathrm{~cm}$ thick and $1.6 \mathrm{~m}$ high, cast with lateral C16 anticracking reinforcement spaced at $15 \mathrm{~cm}$ and C12 stirrups spaced at $10 \mathrm{~cm}$. The abutment backwall is $80 \mathrm{~cm}$ high and $175 \mathrm{~cm}$ thick. Finally, the abutment is flanked by $50 \mathrm{~cm}$ thick wingwalls erected along the abutment body. The concrete for piles, pile cap, abutment backwall, and wingwalls was made of ordinary Portland cement, whose mixing proportion with the water temperature of $20^{\circ} \mathrm{C}$ is shown in Table 1 .

2.1.2. Abutment Cracking. The concrete of the pile cap was poured on January 3, 2017, while that of the abutment backwall was poured on February 12, constituting an age difference of 40 days. Several vertical cracks were spotted on the abutment backwall on February 28, dominated by 4 major cracks symmetrically distributed around the longitudinal center line of the bridge, as shown in Figure 2. The cracks were about $2 \mathrm{~m}$ long, with the middle two cracks extending from the pile cap all the way to the bearing seats on the backwall.

According to field measurements, cracks L1 and R1, indicated in Figure 2, had a width of around $0.4 \mathrm{~mm}$, while cracks L2 and R2 were as wide as $0.5 \mathrm{~mm}$. A core sample was collected from crack L1, revealing that the crack continued through nearly the entire thickness of the pile cap (Figure 3).

2.2. Finite Element Analysis Model. The 3D analysis model of the subject abutment had 31,599 nodes and 25,846 elements. The constraining effect of the pile-soil interaction was taken into consideration by applying a soil spring to the sides of the piles in conjunction with constraints at the pile tips. The $3 \mathrm{D}$ finite element model of the abutment is illustrated in Figure 4(a). In view of the inhibiting effects of internal reinforcement on crack development, the reinforcement scheme of the abutment was included in the model (Figure 4(b)).

\subsubsection{Hydration Heat Model and Atmospheric Temperature} Model. The cracks in a concrete structure can be classified into two types on account of the crack cause: the first type of crack is referred as a structural crack, caused by external load or internal structural force, while the second type is referred 


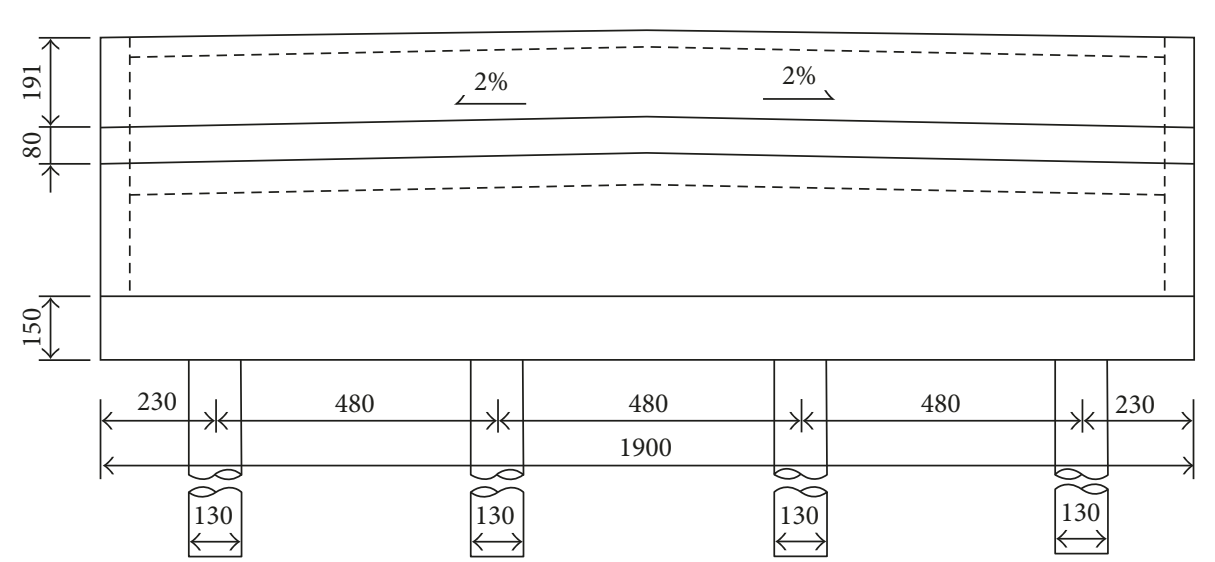

(a) Elevation

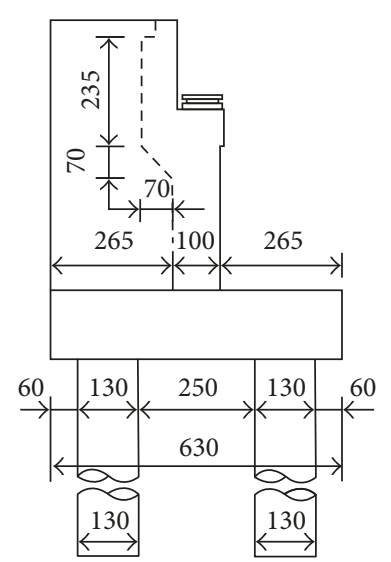

(b) Profile

Figure 1: Abutment structure $(\mathrm{cm})$.

TABle 1: Mix proportion of abutment concrete.

\begin{tabular}{lccccccc}
\hline $\begin{array}{l}\text { Water } \\
\left(\mathrm{kg} / \mathrm{m}^{3}\right)\end{array}$ & $\begin{array}{c}\text { Cement } \\
\left(\mathrm{kg} / \mathrm{m}^{3}\right)\end{array}$ & $\begin{array}{c}\text { Fly ash } \\
\left(\mathrm{kg} / \mathrm{m}^{3}\right)\end{array}$ & $\begin{array}{c}\text { Sand } \\
\left(\mathrm{kg} / \mathrm{m}^{3}\right)\end{array}$ & $\begin{array}{c}\text { Fine stone } \\
\left(\mathrm{kg} / \mathrm{m}^{3}\right)\end{array}$ & $\begin{array}{c}\text { Coarse stone } \\
\left(\mathrm{kg} / \mathrm{m}^{3}\right)\end{array}$ & $\begin{array}{c}\text { Water-cement } \\
\text { ratio }\end{array}$ & $\begin{array}{c}\text { Sand content } \\
(\%)\end{array}$ \\
\hline 155 & 210 & 60 & 626 & 659 & 659 & 0.51 & 33 \\
\hline
\end{tabular}

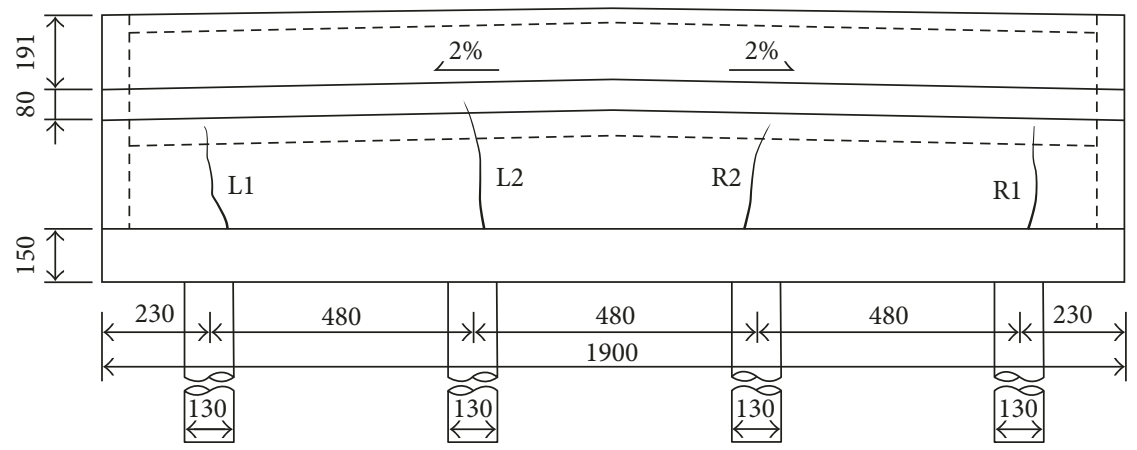

FIgURE 2: Crack distribution on the subject abutment $(\mathrm{cm})$.

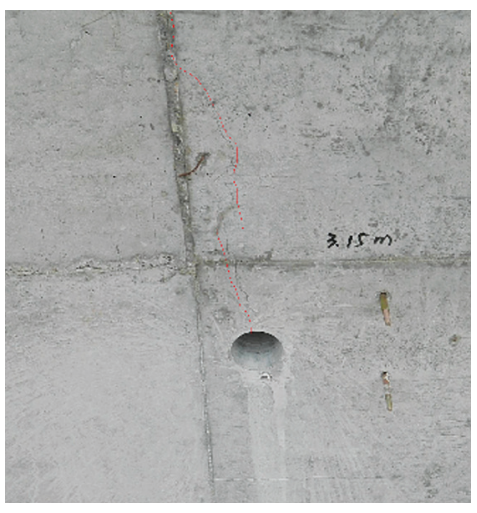

(a) Photo of the crack

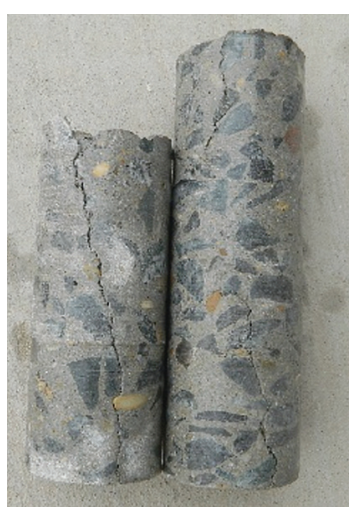

(b) Drilled core
FiguRE 3: Crack "L1" and its drilled core.

as a strain crack, appearing under such classic factors as temperature [11], shrinkage, creep, expansion, humidity, and differential settlement of the foundation.
The load of the bridge superstructure was not acted on the abutment when the cracks in the abutment of the subject bridge appeared during the curing of concrete. As the construction process was determined to be consistent with relevant laws and regulations, the cracks did not appear as the result of construction loads, and the cracks cannot be structural cracks. Hence, they must be strain cracks, likely caused by some type of deformation. Field investigations excluded differential settlement of the foundation as a cause of cracking, indicating that the cracks were likely caused by the concrete shrinkage or differential displacement resulting from temperature changes resulting from the atmosphere and the heat of hydration.

When pouring the abutment, the pile cap had been aged 40 days, so this paper focused on the hydrothermal reaction of the abutment body that occurred from February 12 to February 28.

(1) Thermal Property for the Concrete Material. The heat conduction in the concrete unit was determined by the 


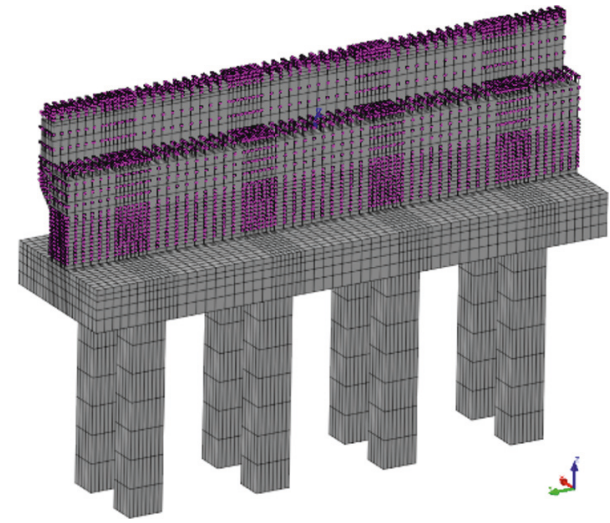

(a) 3D finite element model of the abutment

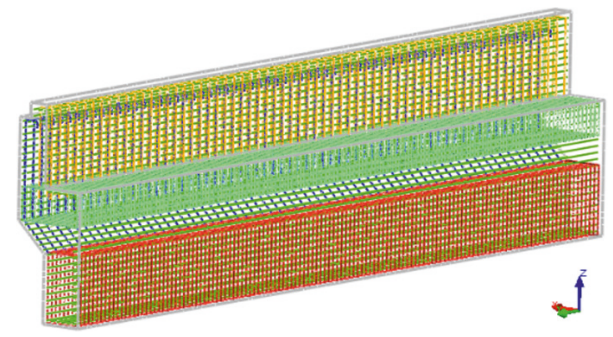

(b) Abutment backwall reinforcement

FIGURE 4: Three-dimensional finite element model of the subject abutment for condition 2 .

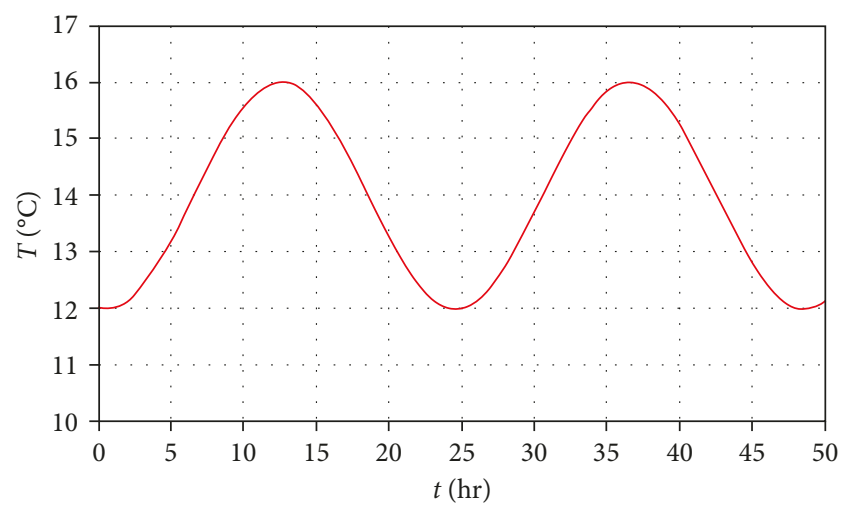

FIGURE 5: Atmospheric temperature model.

specific heat $\mathrm{C}\left(\mathrm{kJ} /\left(\mathrm{kg} \cdot{ }^{\circ} \mathrm{C}\right)\right)$ and the thermal conductivity $\lambda$ $\left(\mathrm{kJ} /\left(\mathrm{m} \cdot \mathrm{hr} \cdot{ }^{\circ} \mathrm{C}\right)\right)$. The mixing ratios of the concrete of the abutment, pile cap, and pile foundation are shown in Table 1; thus, the specific heat $\mathrm{C}$ is $1.176 \mathrm{~kJ} /\left(\mathrm{kg} \cdot{ }^{\circ} \mathrm{C}\right)$, and the thermal conductivity $\lambda$ is $12.42 \mathrm{~kJ} /\left(\mathrm{m} \cdot \mathrm{hr} \cdot{ }^{\circ} \mathrm{C}\right)$.

(2) Model of the Atmospheric Temperature. The model of the atmospheric temperature from February 12 to February 28 was a sine function, whose peak was above $16^{\circ} \mathrm{C}$ and valley value was $12^{\circ} \mathrm{C}$. The model is shown in (1), and its trend is shown in Figure 5.

$$
T(t)=2 \sin \left(\frac{\pi}{12}(t+24)-8\right)+14
$$

where $t$ is the time (hr) and $T(t)$ is the atmospheric temperature corresponding to $t$ hours $\left({ }^{\circ} \mathrm{C}\right)$.

(3) The Convection Characteristics for the Concrete Material. As buried in bedrock all year round, the pile foundation was treated at a fixed temperature complying with the bedrock. All nodes on the pile surface were given a fixed temperature of $20^{\circ} \mathrm{C}$. For the pile cap and abutment, both surfaces were exposed to the atmosphere, so a solid layer with the thickness of $1.5 \mathrm{~cm}$ was established on the surface of the pile cap and abutment, which allows the heat exchange between the pile cap, abutment, and atmosphere. "Exposed surface" was selected as the convection model, and the convection coefficient was a constant $\left(50.23 \mathrm{~kJ} /\left(\mathrm{m}^{2} \cdot \mathrm{hr} \cdot{ }^{\circ} \mathrm{C}\right)\right)$.

(4) Model of the Heat Source. Model of the heat source mainly considered the hydration reaction of the abutment body. When treated as a heat source, the abutment body was considered without exchanging heat with atmosphere, that is, "adiabatic temperature rise." The adiabatic temperature rise of concrete hydration heat is closely related to the concrete mixing ratio and the water temperature for mixing. The concrete of the abutment was ordinary Portland cement, with the concrete mix proportion shown in Table 1. Taking into account the concrete mix proportion and the water temperature for mixing, we obtained a proper model of adiabatic temperature rise for the abutment body by checking the Japanese norm JSCE-SSCS 2002 [12], as shown in the following formula:

$$
Q(t)=Q \operatorname{int}\left[1-e^{-r\left(t-t_{0}\right)}\right]
$$

where $Q_{\text {int }}$ is the highest of adiabatic temperature rise for abutment concrete $\left({ }^{\circ} \mathrm{C}\right), r$ is the thermal conductivity coefficient $\left(\mathrm{m}^{2} / \mathrm{hr}\right), t_{0}$ is the starting time of hydration heat for concrete (day), $t$ is the cumulative time of hydration heat for concrete (day), $Q(t)$ is the adiabatic temperature rise for concrete accumulated over $t$ days $\left({ }^{\circ} \mathrm{C}\right)$.

According to the actual mix proportion of the abutment concrete, we determined the value of the parameters shown in Table 2.

Through the relevant parameters in Table 2, we obtained the model of adiabatic temperature rise for the abutment body, as shown in Figure 6.

Based on the hydration heat model discussed earlier and the atmospheric temperature model, hydrothermal analysis was executed using FEA, and the following results were obtained.

The hydration heat of the concrete began with the start of the abutment pouring. Thus, taking into account the model of the atmospheric temperature and bedrock temperature, the highest temperature changes over time of hydration heat for the pile foundation, pile cap, and abutment are shown in Figure 7. Figures $8(\mathrm{a})-8(\mathrm{f})$, corresponding to the six representative time series, show the temperature of the abutment profile.

As seen from Figure 7, the temperature of the abutment body remarkably rose from $20^{\circ} \mathrm{C}$ to $36^{\circ} \mathrm{C}$ within three days after the body was poured (February 12 to February 15), and then, the temperature began to drop. When cracks went 
TABLE 2: Related parameters of adiabatic temperature rise for abutment concrete.

\begin{tabular}{lcc}
\hline$Q_{\text {int }}\left({ }^{\circ} \mathrm{C}\right)$ & $t_{0}($ day $)$ & $r\left(\mathrm{~m}^{2} / \mathrm{hr}\right)$ \\
\hline 36.1 & 0 & 0.762 \\
\hline
\end{tabular}

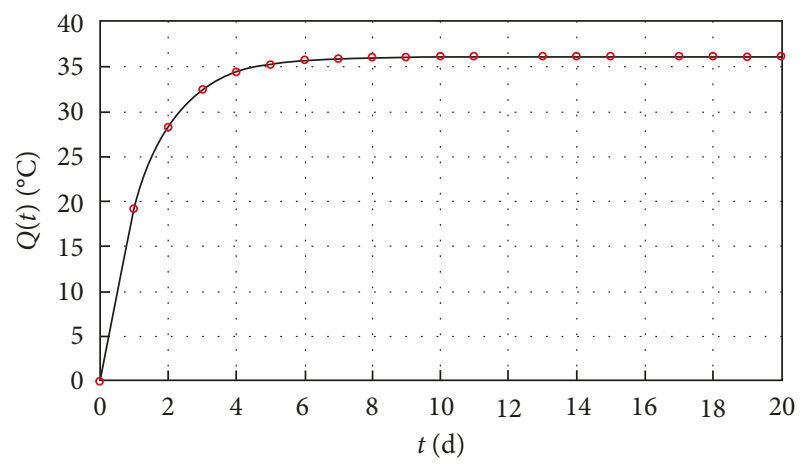

Figure 6: Model of adiabatic temperature rise for the abutment.

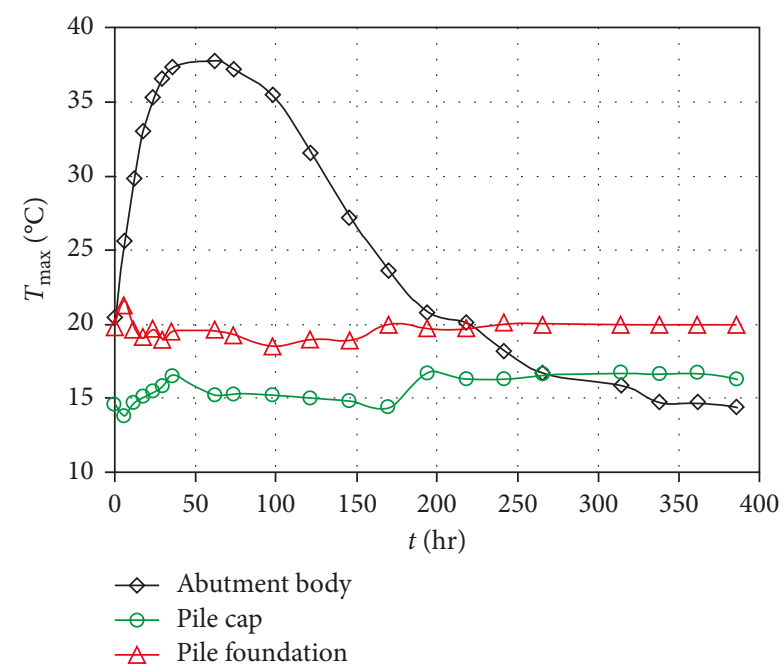

FIGURE 7: Change of abutment temperature with time of hydration heat.

through the body of abutment (February 28, its temperature was $14.4^{\circ} \mathrm{C}$. As buried in bedrock all year round, the temperature of the pile foundation was basically consistent with the bedrock, at about $20^{\circ} \mathrm{C}$. Because its surface was exposed to atmosphere mostly, the temperature of the pile cap fluctuated between 12 and $14^{\circ} \mathrm{C}$. However, due to the effects of the abutment body and pile foundation temperature, the temperature of the junction area of them would vary differently. In summary, the temperature model of the pile foundation, pile cap, and abutment body can determine the accuracy of the hydration heat model for the abutment body.

The crack coefficient $i$ value was used to predict whether the temperature cracks occur:

$$
i=\frac{f_{t}}{\sigma_{T}}
$$

where $f_{t}$ is the tensile strength of concrete $(\mathrm{MPa})$ and $\sigma_{T}$ is the temperature stress $(\mathrm{MPa})$.

According to the hydrothermal analysis using FEA, the crack coefficient of the abutment can be obtained, as shown in Figure 9.

When the $i$ value is greater than 1.5, cracks can be prevented. Figure 9 shows the minimum $i$ value of 1.1, which was mainly concentrated in the area of the abutment body above pile foundations; that is, the construction cracks will be generated in these areas.

2.2.2. Load Calculation. In order to study the generation mechanism and development process of the vertical cracks for abutment and use them as the basis for the parametric analysis of the abutment, it was not enough to rely on the hydrothermal analysis using FEA alone. In this paper, a nonlinear analysis of the abutment was carried out on the basis of the results of hydration analysis considering the atmospheric temperature.

According to the construction record, the vertical cracks in the abutment body belong to the through cracks, and the through cracks are often caused by the deformation on account of the concrete cooling gradually after the mass concrete develops to a certain extent. Therefore, in the nonlinear analysis process, the load was "cooling," mainly including the following cooling models.

(1) Equivalent Temperature Difference of Shrinkage. In order to compare the effects of shrinkage with the effects of hydration heat and atmospheric temperature, in this study, shrinkage is converted to an equivalent temperature differential. The shrinkage is first calculated in accordance with JTGD62-2012 Code for Design of Highway Reinforced Concrete and Prestressed Concrete Bridges and Culverts [13], in which the concrete shrinkage stress can be calculated using the following equations:

$$
\begin{aligned}
\varepsilon_{\mathrm{cs}}\left(t, t_{s}\right) & =\varepsilon_{\mathrm{cso}} \beta_{s}\left(t-t_{s}\right), \\
\beta_{s}\left(t-t_{s}\right) & =\left[\frac{t-t_{s}}{350(h / 100)^{2}+\left(t-t_{s}\right)}\right]^{0.5},
\end{aligned}
$$

where $t$ is the concrete age at the moment of consideration (day); $t_{s}$ is the concrete age when the shrinkage begins (day), set at $3 \mathrm{~d} ; \varepsilon_{\mathrm{cs}}\left(t, t_{s}\right)$ is the shrinkage stress value at $t$ and $t_{s} ; \varepsilon_{\text {cso }}$ is the nominal shrinkage coefficient, which is given in Table $3 ; \beta_{s}\left(t-t_{s}\right)$ is the shrinkage development factor; $h$ is the theoretical thickness of the component under consideration ( $\mathrm{mm}$ ), where $h=2 A / u$ when $A$ is the cross-sectional area of the component $\left(\mathrm{mm}^{2}\right)$; and $u$ is the peripheral length of the component in contact with the open air $(\mathrm{mm})$.

In Table 3, RH is the annual average relative humidity in atmosphere, and in this case, $\mathrm{RH}$ is $70 \%$ to $99 \%$; thus, $\varepsilon_{\mathrm{cso}}$ is $3.1 \times 10^{-4}$. 


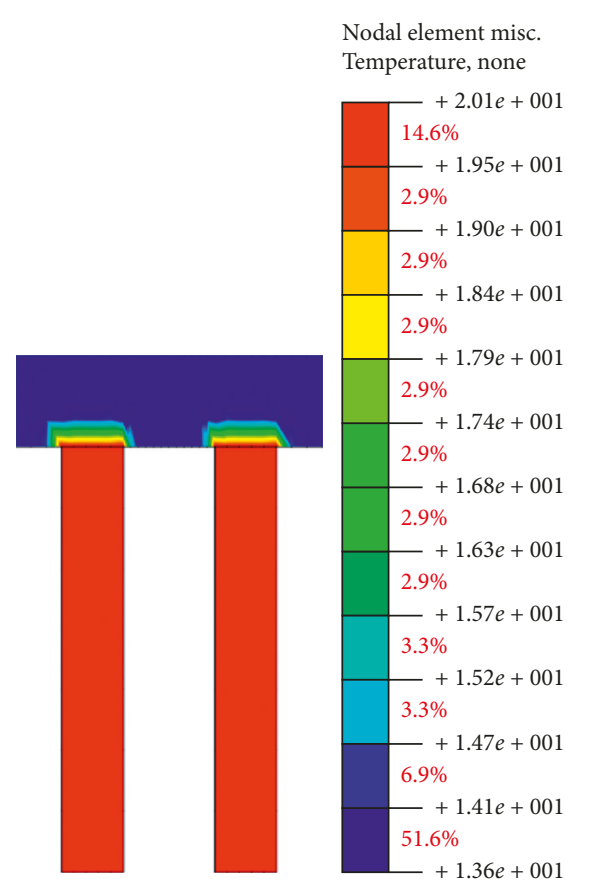

(a) $t=0 \mathrm{hr}$

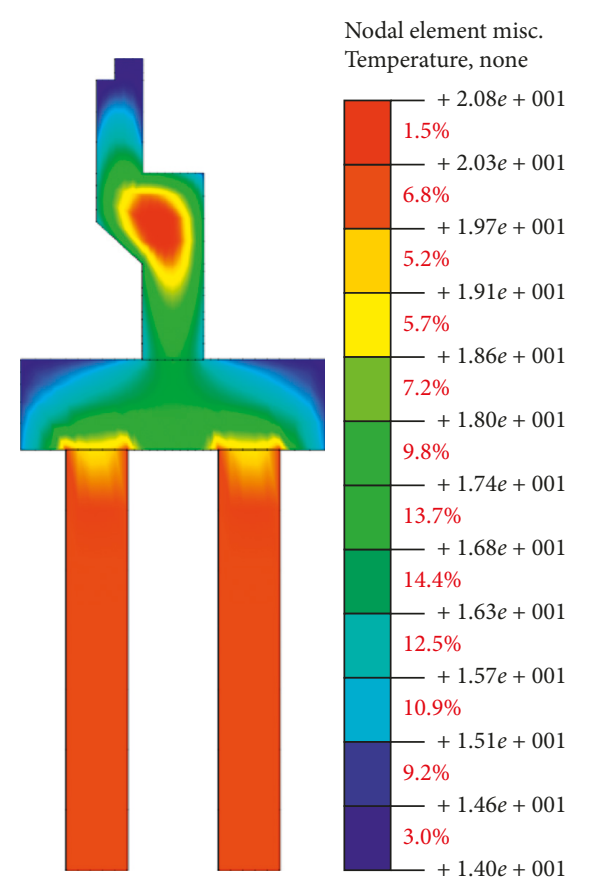

(d) $t=168 \mathrm{hrs}$

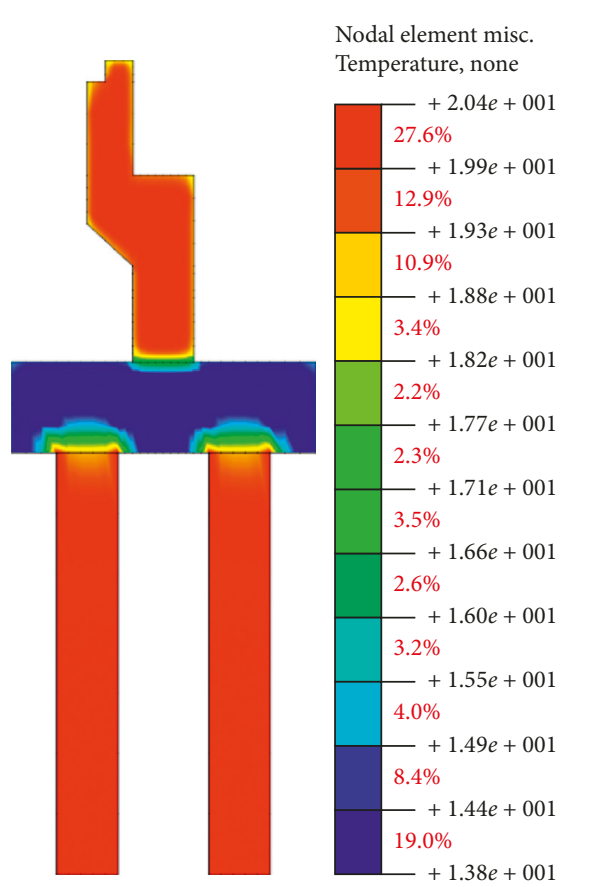

(b) $t=8 \mathrm{hrs}$

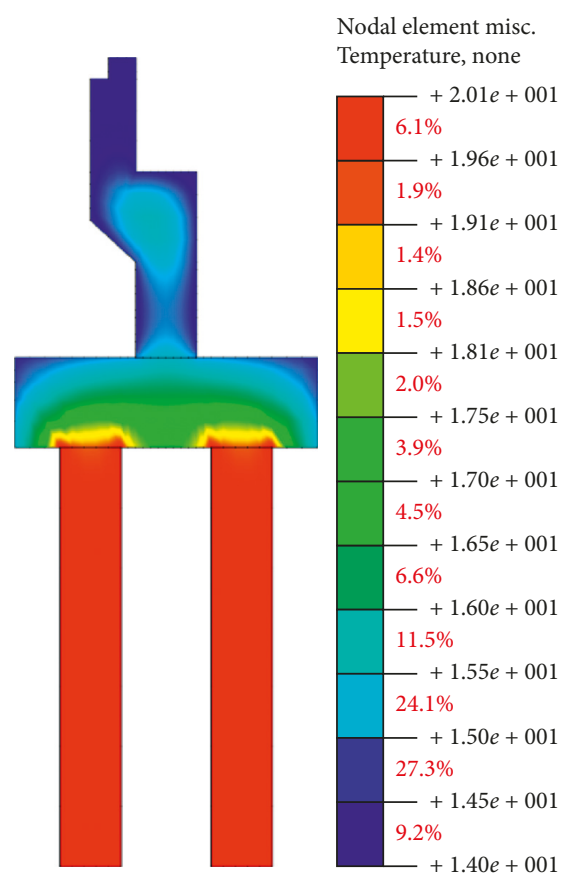

(e) $t=240 \mathrm{hrs}$

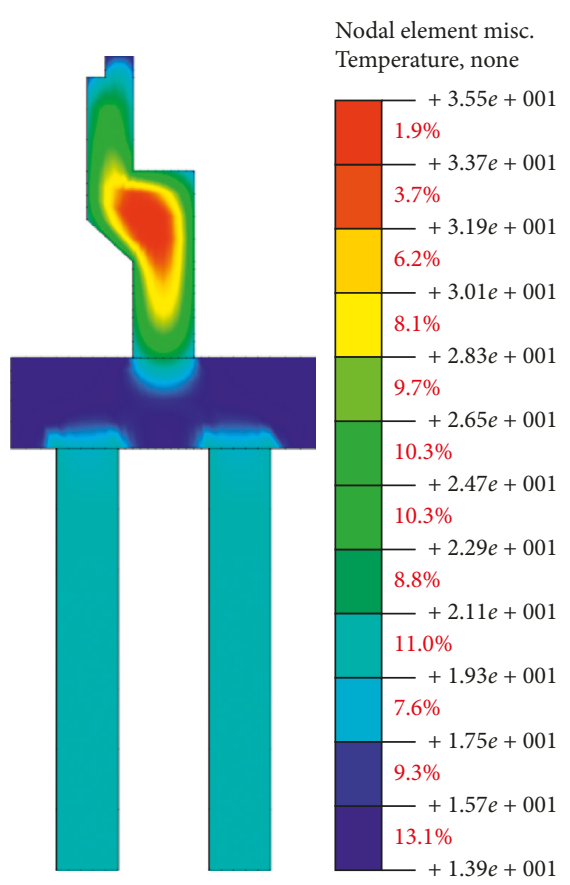

(c) $t=50 \mathrm{hrs}$

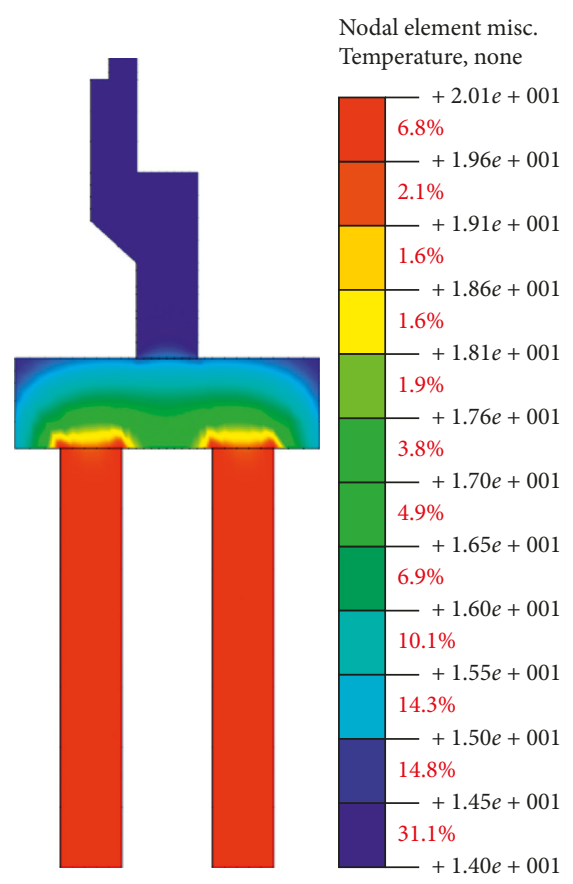

(f) $t=384 \mathrm{hrs}$

Figure 8: Abutment temperature.

As stated before, there were nearly 40 days between the casting of the pile cap and the casting of the backwall. The concrete in the pile cap and abutment backwall was believed to begin shrinking 3 days after the pouring of each component was completed. The pile cap concrete was 55 days old and abutment backwall concrete was 16 days old when the backwall first showed cracks. The primary parameters for determining the shrinkage stress in the cushion cap and abutment body with no constraints at the time of cracking were calculated according to (4) and (5) and are listed in Table 4.

Assuming the linear expansion coefficient of concrete, $\alpha$, to be $1.0 \times 10^{-5} /{ }^{\circ} \mathrm{C}$, the equivalent temperature of differential shrinkage between the pile cap and abutment backwall concrete, $T_{s}$, can be determined using the following formula: 


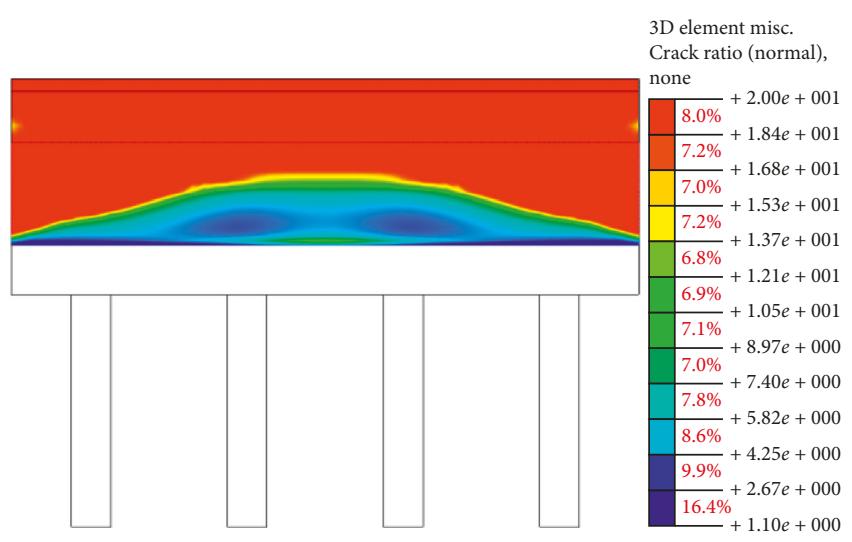

FIgURE 9: Temperature crack coefficient of the abutment.

TABle 3: Nominal shrinkage coefficient $\varepsilon_{\text {cso }}\left(\times 10^{-4}\right)$.

\begin{tabular}{lc}
\hline $40 \% \leq \mathrm{RH}<70 \%$ & $70 \% \leq \mathrm{RH}<99 \%$ \\
\hline 5.26 & 3.10
\end{tabular}

TABLE 4: Concrete shrinkage parameters and strain.

\begin{tabular}{lccccc}
\hline Parameter & $\begin{array}{c}t \\
(\text { day })\end{array}$ & $\begin{array}{c}h \\
(\mathrm{~mm})\end{array}$ & $\begin{array}{c}\beta_{s}\left(t-t_{s}\right) \\
\left(\times 10^{-2}\right)\end{array}$ & $\begin{array}{c}\varepsilon_{\mathrm{cso}} \\
\left(\times 10^{-4}\right)\end{array}$ & $\begin{array}{c}\varepsilon_{\mathrm{cs}}\left(t, t_{s}\right) \\
\left(\times 10^{-6}\right)\end{array}$ \\
\hline Pile cap & 55 & 1211.54 & 3.18 & 3.1 & 12.4 \\
Abutment backwall & 16 & 807.42 & 2.39 & 3.1 & 9.34 \\
\hline
\end{tabular}

$$
T_{s}=\frac{9.34 \times 10^{-6}-1.24 \times 10^{-5}}{1.0 \times 10^{-5}},
$$

yielding an equivalent temperature of $-0.31^{\circ} \mathrm{C}$, indicating an equivalent cooling effect from differential shrinkage.

(2) The Abutment Cooling $\Delta T_{i}$ on Account of Hydration Heat and Atmospheric Temperature. Taking into account the influence of atmospheric temperature on the abutment body, its concrete hydration heat developed to peak will gradually cool down. The data that the temperature of the abutment body changed with the time of hydration heat had been calculated, as shown in Figure 8. The node temperature of the abutment body varies with the coordinates of nodes from Figure 8. For node $i$, the maximum temperature was recorded as $T_{i \max }$, the corresponding minimum temperature was recorded as $T_{i \mathrm{~min}}$, and the temperature drop $\Delta T_{i}$ was $T_{i \min }-T_{i \max }$.

2.3. Calculation Conditions. Two conditions were evaluated to determine the cause of cracking in the subject abutment, as described in this section.

2.3.1. Condition 1. The equivalent temperature difference of concrete between the abutment body and pile cap $T_{s}$.

This condition described the effect of differential concrete shrinkage between the abutment backwall and the pile cap. As determined in the calculations of Section 2.2.2(1), the

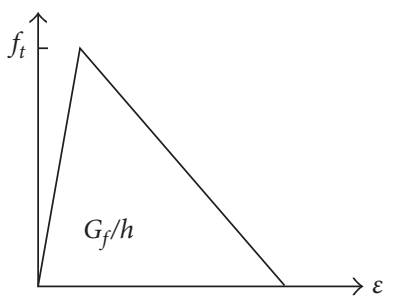

Figure 10: Tensile model with linearized softening.

equivalent temperature differential describing this concrete shrinkage, $T_{s}$, was $-0.31^{\circ} \mathrm{C}$, and it was applied to the abutment body. Considering the constraint of pile foundations, the model of the pile cap, abutment body, and pile foundations was established by using Midas/FEA.

2.3.2. Condition 2. The abutment cooling on account of hydration heat and atmospheric temperature $\Delta T_{i}+$ the equivalent temperature difference of concrete between the abutment body and pile cap $T_{s}$.

This condition considered the comprehensive temperature cooling, including the temperature cooling $\Delta T_{i}$ of the abutment body as a result of hydration heat and atmospheric temperature and the equivalent temperature $T_{s}$ on account of the concrete shrinkage difference between the abutment body and pile cap. Simultaneously, the constraint of the pile foundation was considered.

Considering the model of atmospheric temperature, we extracted the cooling data $\Delta T_{i}$ of all nodes $(i=1 \sim 50,946)$ of the abutment body and attached the equivalent temperature $T_{s}$. In the nonlinear analysis, the comprehensive temperature cooling $\Delta T_{i}+T_{s}$ was applied to all nodes of the abutment body corresponding to the body node number, respectively.

\subsection{Material Constitutive Relations}

2.4.1. Constitutive Tensile Relationship of the Concrete Material. The Midas/FEA analysis accounts for the nonlinear properties of the concrete material in order to determine the causes of the observed cracking. The concrete material parameters used adopt the total strain crack model, a type of the discrete crack model that evaluates crack behavior according to either a fixed crack model or a rotating crack model. In the fixed crack model, once determined, the cracking direction does not change in any case, while for the rotating crack model, the cracking direction changes with the change in the direction of principle stress. Although the former can accurately describe the physical properties of a crack in detail, when a structure with a fixed orthogonal crack is compared with a structure with a nonorthogonal crack, the structural rigidity and strength are overevaluated. In comparison, the rotating crack model requires no knowledge of past cracking states, so its calculation process is more simple and convergent. Because of its merits, the rotating crack model has long been applied to the nonlinear analysis of reinforced concrete structures. Accordingly, the rotating crack model was chosen for use in this study as well. 


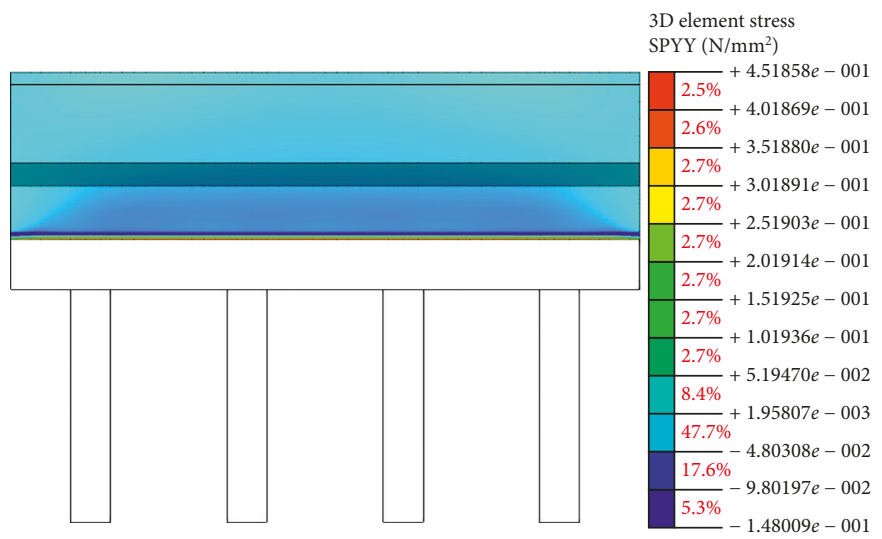

FIgURE 11: Lateral stress distribution in the abutment under Condition $1(\mathrm{MPa})$.

The total stress cracking model adopts a linear softening model that exhibits softening when the tensile strength of the base material is exceeded, as shown in Figure 10.

The major constitutive equations for the linearized softening tensile model are shown below:

$$
\begin{aligned}
\varepsilon_{u \cdot \min }^{\mathrm{cr}} & =\frac{f_{t}}{E}, \\
f_{t} & =\sqrt{2 \frac{G_{f} E}{h}},
\end{aligned}
$$

where $G_{f}$ indicates the tensile fracture energy of concrete, $E$ indicates the elastic modulus of concrete, $h$ denotes the crack width, $f_{t}$ denotes the tensile stress in the concrete, and $\varepsilon_{u \cdot \min }^{\mathrm{cr}}$ denotes the minimum ultimate crack strain.

\subsubsection{Bonding Model of Reinforced Concrete. Considering} that the slippage between steel and concrete in a reinforced concrete structure was affected by cracks, a bond-slip model can be used to simulate this effect. The FEA software uses a constitutive model based on the theory of total mass to describe the bond-slip model. Assuming that the normal direction of materials was linear elasticity and the tangential direction was nonlinear, the bond-slip model can be described as follows:

$$
\begin{aligned}
& t_{n}=k_{n} \Delta u_{n}, \\
& t_{t}=f_{t}(d t) .
\end{aligned}
$$

Deriving the right side of (9) and (10) for relative displacement, the tangent stiffness is as follows:

$$
\left[\begin{array}{ll}
D_{11}=k_{n} & D_{12}=0 \\
D_{21}=0 & D_{22}=\frac{\partial f_{t}}{\partial d_{t}}
\end{array}\right] .
$$

\section{Results and Discussion}

3.1. Analysis of Crack Cause. The Midas/FEA software package was used to create a 3D nonlinear finite element analysis model of the subject abutment. Under Condition 1, the focus of the research was on the effect of the difference in concrete shrinkage between the abutment backwall and the pile cap on the stress in the abutment backwall. Under Condition 2, attention was paid to all potential crackinfluencing factors: the atmospheric temperature changes, hydration heat of concrete, and equivalent temperature of concrete shrinkage difference. The major results and analysis are as follows.

3.1.1. Condition 1. Under this condition, the effect of the difference in concrete shrinkage between the abutment backwall and the pile cap on the abutment is considered in isolation. Meanwhile, this model took the constraint of pile foundations into account. When the equivalent differential shrinkage temperature $T_{s}=-0.31^{\circ} \mathrm{C}$ is applied to the abutment backwall, the lateral stress distribution shown in Figure 11 is obtained.

Figure 11 depicts the distribution of the lateral normal stress in the abutment when the constraints of the pile foundation on the abutment and pile cap were taken into consideration, and the lower middle portion of the abutment was the most stressed area, with a maximum tensile stress of about $0.45 \mathrm{MPa}$, which is lower than the standard tensile strength of $2.01 \mathrm{MPa}$ for abutment concrete. As a result, no cracks appeared on the abutment for this equivalent temperature change, which correlates with the differential shrinkage between the pile cap and abutment.

3.1.2. Condition 2. The condition of temperature cooling $\Delta T_{i}+T_{s}$ acted on the abutment body. Considering the constraint of pile foundations, the following calculation results were obtained by the Midas/FEA analysis.

Taking the change of the maximum temperature of the abutment body $T_{\max }$ with the hydration heat time of the abutment body $t$ as a reference, the development of cracks in the abutment was described as in Figure 12. When $T_{\max }$ decreased from $35.5^{\circ} \mathrm{C}$ to $18.2^{\circ} \mathrm{C}$ (i.e., 10 days after abutment pouring), the abutment began to form vertical cracks at the top of both sides of pile foundations, namely, cracks "L1" 


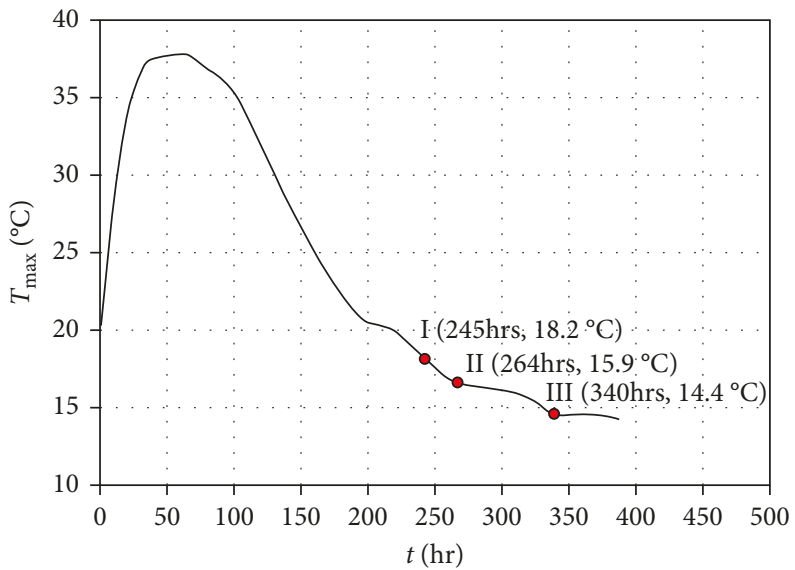

I: generation of $\mathrm{L} 1$ and $\mathrm{R} 1$ cracks

II: generation of L2 and R2 cracks

III: cracks run through abutment

FIGURE 12: Main crack state corresponding to hydration time of the abutment body.

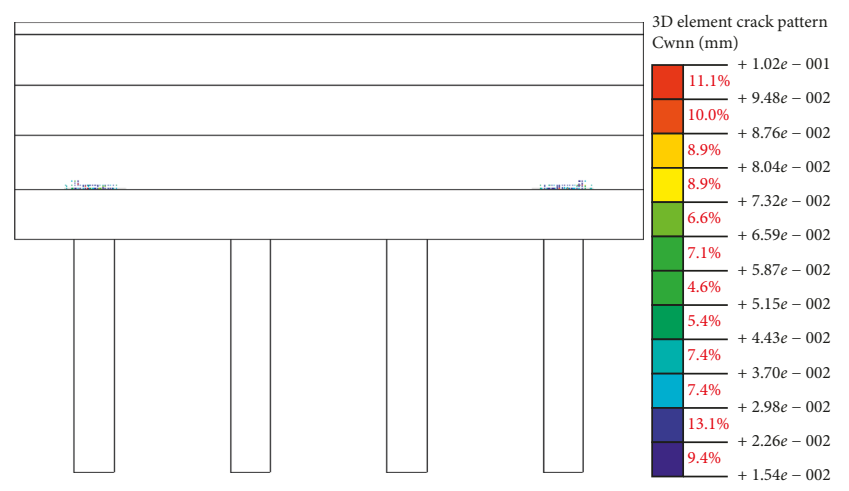

(a) State I (MPa)

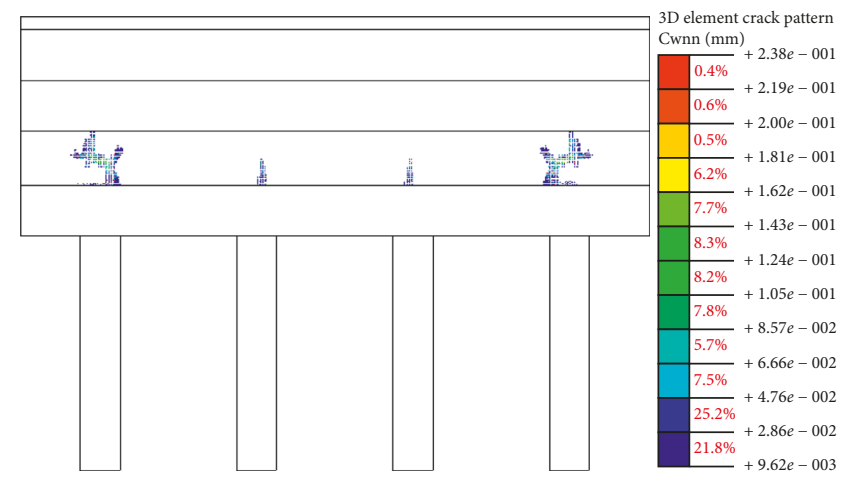

(b) State II (mm)

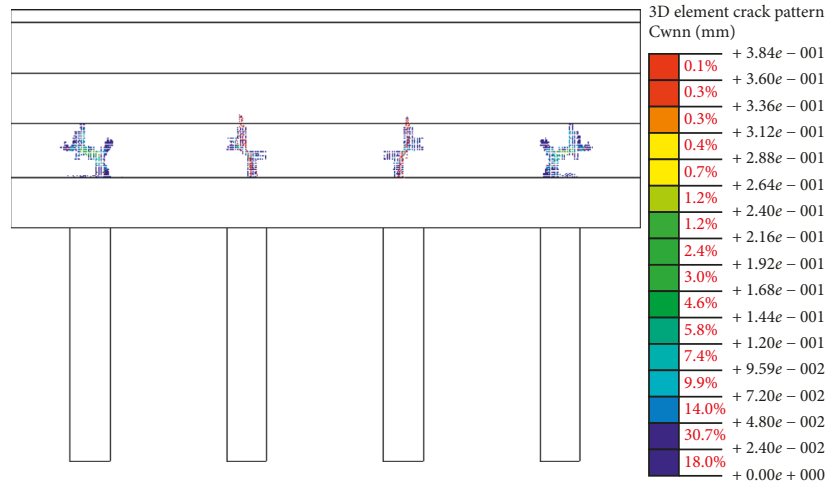

(c) State III $(\mathrm{mm})$

Figure 13: Crack development process and crack width in the abutment.

TABLE 5: Evaluated crack-control reinforcement schemes.

\begin{tabular}{lcccc}
\hline Reinforcement scheme & I & II & III & IV \\
\hline Diameter $(\mathrm{mm})$ & 10 & 12 & 14 & 16 \\
Interval $(\mathrm{cm})$ & 10 & 12.5 & 15 & 20 \\
Single bar area $\left(\mathrm{mm}^{2}\right)$ & 78.5 & 113.1 & 153.9 & 201.1 \\
Reinforcement ratio (\%) & 0.30 & 0.30 & 0.30 & 0.30 \\
\hline
\end{tabular}

and "R1." And the cracks are shown in Figure 13(a), which shows that the crack width was $0.102 \mathrm{~mm}$.

As the maximum temperature of the abutment body $T_{\max }$ was further reduced to $15.9^{\circ} \mathrm{C}$ (i.e., 11 days after abutment pouring), the abutment began to form vertical cracks at the top of middle pile foundations, namely, cracks "L2" and "R2," whose widths were $0.238 \mathrm{~mm}$, as shown in Figure 13(b). 


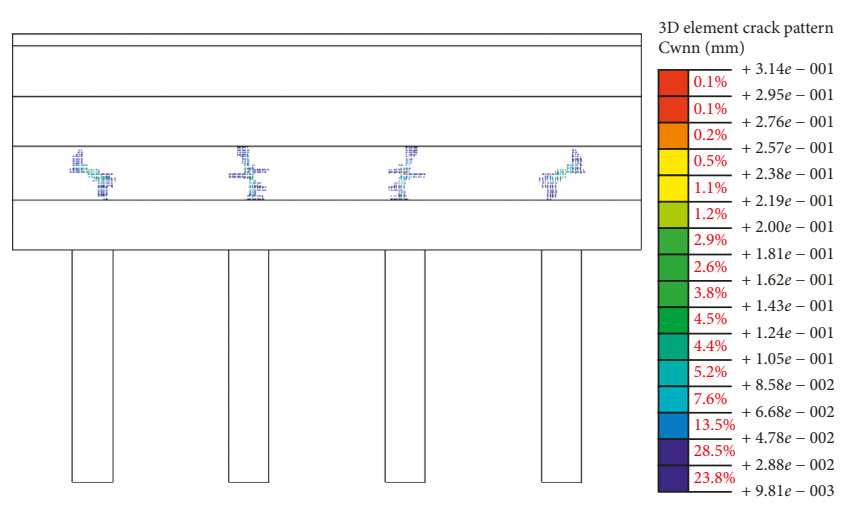

(a) Reinforcement scheme I

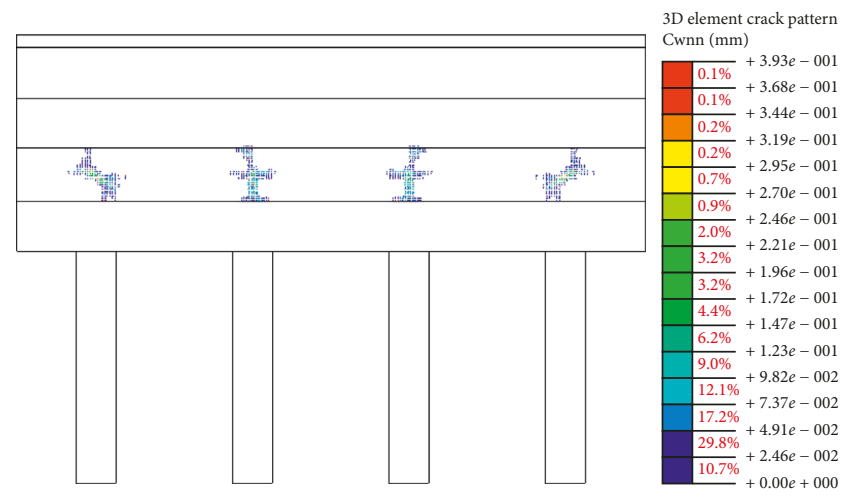

(c) Reinforcement scheme III

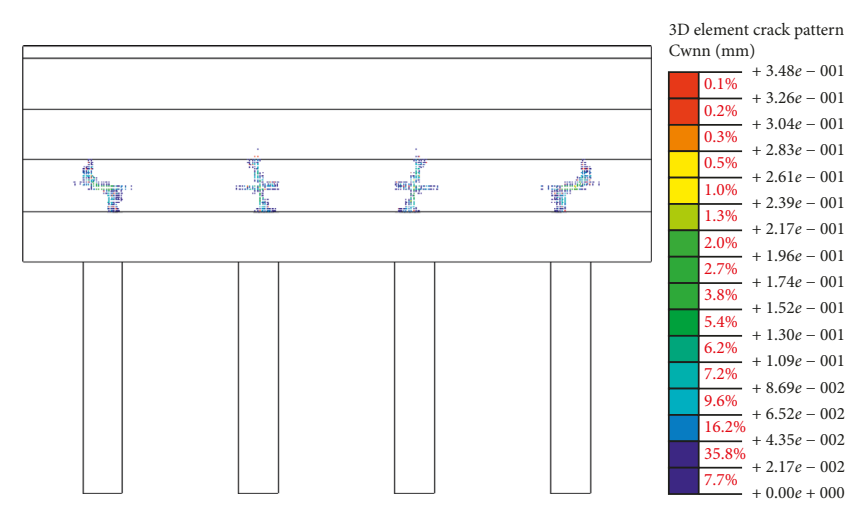

(b) Reinforcement scheme II

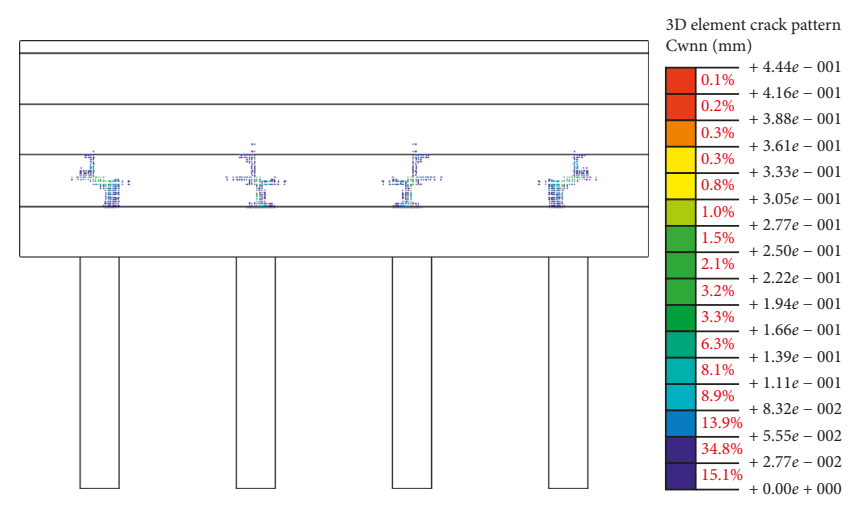

(d) Reinforcement scheme IV

FIGURE 14: Crack widths in the abutment for different reinforcement schemes (mm).

When the maximum temperature of the abutment body $T_{\max }$ was reduced to approximately $14^{\circ} \mathrm{C}$ (i.e., 14 days after the abutment pouring), the four main cracks had penetrated the abutment body. The cracks "L1" and "R1" were $0.365 \mathrm{~mm}$ wide and $1.74 \mathrm{~m}$ high, and the cracks "L2" and "R2" were $0.384 \mathrm{~mm}$ wide and $1.85 \mathrm{~m}$ high, as shown in Figure 13(c).

At the moment, the L1, L2, R1, and R2 cracks were nearly the same as the vertical cracks observed in the abutment of the flyover at Cuixiang Road. In view of the computational results of Conditions 1 and 2, it can be concluded that the difference in concrete shrinkage between the abutment backwall and pile cap is not the primary cause of the vertical cracks in the abutment backwall. Instead, the combined effects of hydration heat, atmospheric temperature differential, and concrete shrinkage differential cause a deformation in the abutment backwall to occur. This deformation is constrained by the pile foundation, causing the major cracks to proceed vertically upward from the top of the pile cap.

3.2. Analysis of Crack-Influencing Factors. The analysis in Section 3.1 reveals the stress mechanism causing vertical cracks in the abutment backwall under secondary effects such as concrete shrinkage and temperature change. In order to prevent the appearance of these vertical cracks, the authors analyze different factors affecting the behavior of the abutment backwall, including horizontal crack-control
TABLE 6: Maximum crack widths in the abutment under different reinforcement schemes.

\begin{tabular}{lcccc}
\hline Reinforcement scheme & I & II & III & IV \\
\hline Maximum crack width $(\mathrm{mm})$ & 0.314 & 0.348 & 0.393 & 0.444 \\
\hline
\end{tabular}

reinforcement, pile foundation rigidity, concrete age difference between the pile cap and abutment backwall, and the inclusion of a postcast strip.

3.2.1. Horizontal Crack-Control Reinforcement. Keeping the reinforcement ratio and $20 \mathrm{~cm}$ stirrup interval fixed, the change in abutment backwall cracking with the change in diameter and interval of horizontal crack-control reinforcement was evaluated. To this end, four reinforcement schemes using reinforcing diameters from 10 to $16 \mathrm{~mm}$ and spacing intervals from 10 to $20 \mathrm{~cm}$, shown in Table 5 , are compared.

The four reinforcement schemes are calculated under Condition 2 with the results as provided in Figure 14.

The maximum crack widths corresponding to reinforcement schemes I, II, III, and IV shown in Figure 14 are summarized in Table 6.

The data provided in Table 6 suggest that, for the same reinforcement ratio, the maximum crack width increases with the increasing diameter and interval of horizontal crackcontrol reinforcement. In other words, the arrangement of 


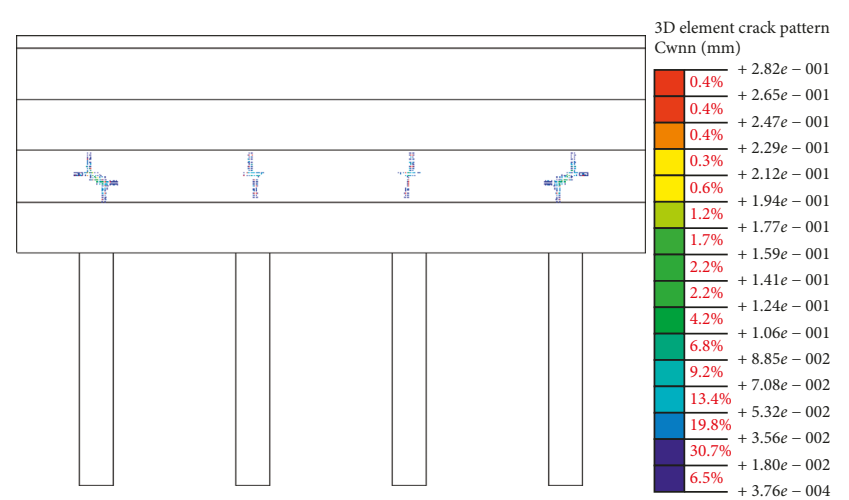

(a) Pile diameter $1.0 \mathrm{~m}$

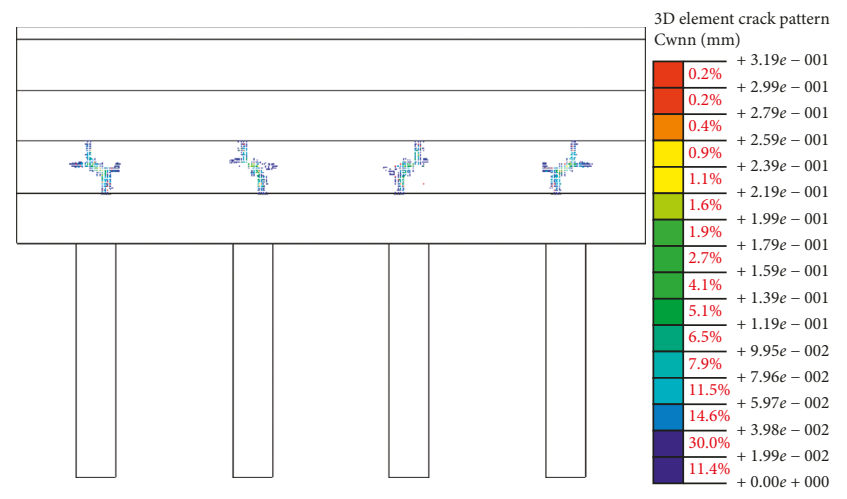

(c) Pile diameter $1.2 \mathrm{~m}$

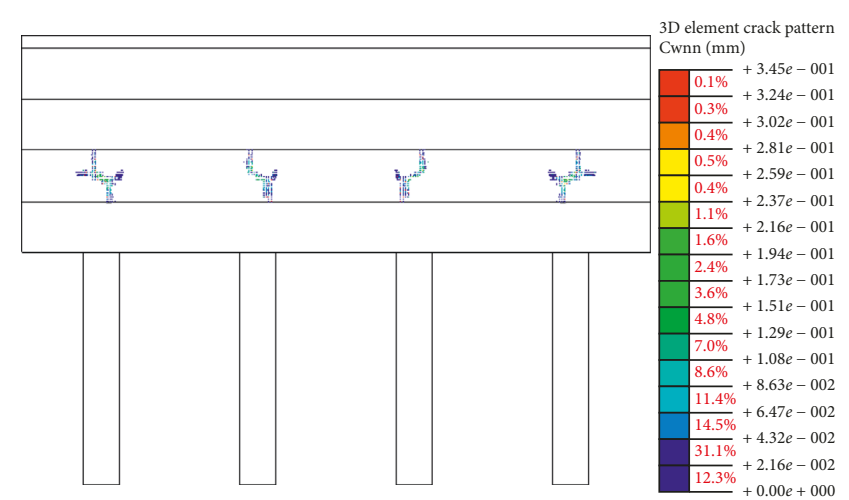

(b) Pile diameter $1.1 \mathrm{~m}$

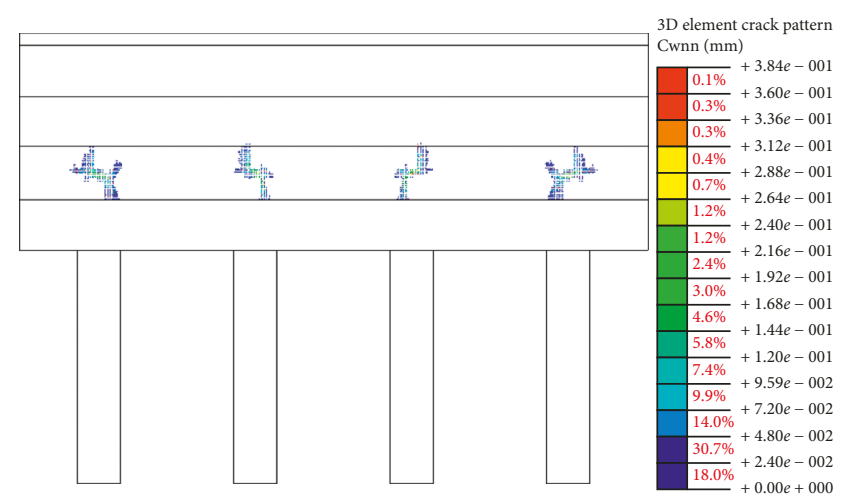

(d) Pile diameter $1.3 \mathrm{~m}$

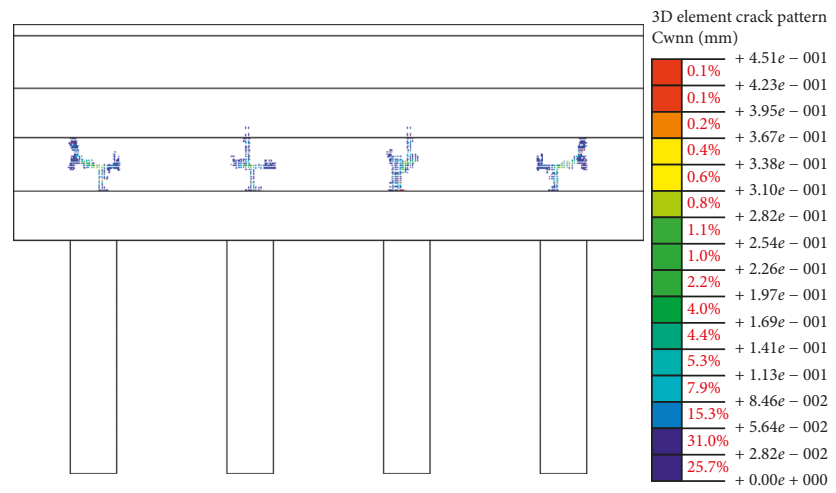

(e) Pile diameter $1.4 \mathrm{~m}$

FIGURE 15: Abutment crack geometry under different pile diameters (mm).

horizontal crack-control reinforcement in a "thin but dense" manner most successfully controls the appearance of vertical cracks on the abutment during construction. For the subject abutment, when the reinforcement ratio is held constant, the use of a "thin but dense" arrangement (C10 reinforcement at $10 \mathrm{~cm}$ intervals) can reduce the crack width by $29.3 \%$ when compared with a "thick but sparse" arrangement (C16 reinforcement at $20 \mathrm{~cm}$ intervals).

3.2.2. Pile Foundation Rigidity. According to the stress mechanisms in the abutment backwall during construction, the backwall tends to deform under the effect of secondary factors such as concrete shrinkage and temperature change,
TABLE 7: Maximum crack widths in the abutment backwall for different pile diameters.

\begin{tabular}{lccccc}
\hline Pile diameter $(\mathrm{m})$ & 1.0 & 1.1 & 1.2 & 1.3 & 1.4 \\
Maximum crack width $(\mathrm{mm})$ & 0.282 & 0.345 & 0.319 & 0.384 & 0.451 \\
\hline
\end{tabular}

but this deformation is constrained by the pile foundation, resulting in the formation of vertical cracks on the abutment above the pile locations. Therefore, it is necessary to analyze the effect of pile rigidity on the stress in the abutment. Piles with diameters of $1.0 \mathrm{~m}, 1.1 \mathrm{~m}, 1.2 \mathrm{~m}, 1.3 \mathrm{~m}$, and $1.4 \mathrm{~m}$ were evaluated to provide a comparative analysis under Condition 2. The results are provided in Figure 15, and the calculated crack widths in the abutment backwall for each pile size are summarized in Table 7. 


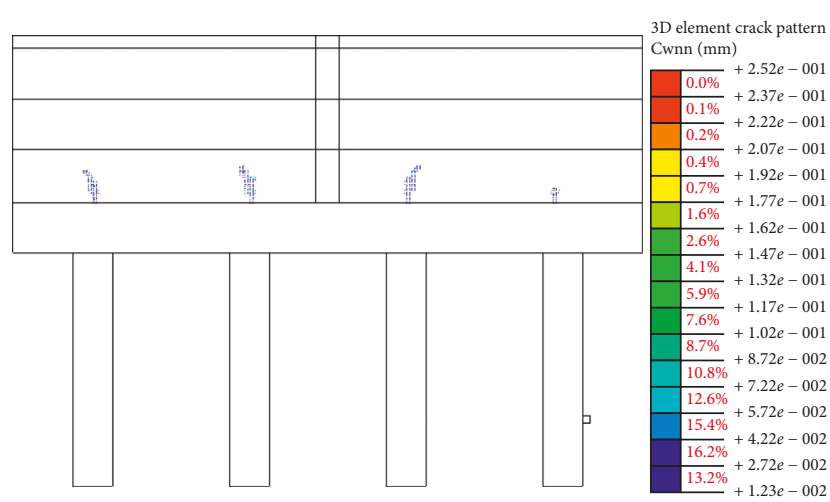

FIGURE 16: Crack width in the abutment after casting of the postcast strip $(\mathrm{mm})$.

Clearly, the rigidity of the piles has a significant effect on the stress in the abutment during construction. As can be seen in Table 7, as the rigidity of the piles increases with increasing pile diameter, so does the constraining effect on the abutment backwall. As a result, the width of the vertical cracks in the abutment backwall increases with the increase in pile diameter.

3.2.3. Inclusion of a Postcast Strip. In order to examine the effect of the postcast strip on crack development, a $70 \mathrm{~cm}$ thick postcast strip was placed in the middle of the abutment backwall model. The concrete construction procedure was assumed as follows: (1) erect the reinforcement cage for the pile cap and abutment backwall and then cast the pile cap; (2) complete the reinforcement for the left and right sides of the abutment and cast the abutment backwall on the left and right sides, leaving the reinforcement in the postcast strip location exposed; (3) pour the concrete to form the left and right abutment caps; and (4) connect the exposed reinforcement in the postcast strip and cast the strip concrete 60 days later.

The Midas/FEA software package was used to carry out a nonlinear analysis of the abutment during construction under Condition 2, yielding the results shown in Figure 16.

A comparison of the results shown in Figure 16 for an abutment including a postcast strip with those shown in Figure 13(c) for an abutment with no postcast strip reveals a significant decrease in the crack width when a postcast strip is used. The maximum crack width in an abutment without a postcast strip is $0.384 \mathrm{~mm}$, while in an abutment with a postcast strip, the crack width is $0.252 \mathrm{~mm}$, representing a $34.4 \%$ reduction in addition to a significant reduction in the crack height.

\subsubsection{Difference in Pile Cap and Abutment Backwall Concrete} Age. The concrete of the abutment backwall was not poured until 40 days after the pouring of the pile cap. According to the results computed in Section 2.2.2(1), the equivalent temperature change of the concrete shrinkage differential between the pile cap and the abutment backwall is $T_{s}=-0.31^{\circ} \mathrm{C}$.
When the constraining effects of the piles are taken into consideration after the equivalent shrinkage temperature drop acts on the abutment backwall, the maximum normal stress on the abutment backwall is only $0.45 \mathrm{MPa}$ (Figure 11), which is far lower than the standard tensile strength of 2.01 MPa of abutment body concrete. As a result, the contribution of the difference in age of the pile cap and abutment backwall concrete to the vertical cracks in the abutment backwall may be safely ignored.

\section{Conclusions}

In order to determine the causes of vertical cracks observed in an abutment backwall during the construction of the flyover located at Cuixiang Road, a total strain crack model was used to create a 3D finite element nonlinear analytic model of the abutment backwall, pile cap, and foundation. In the process, the stress mechanisms in the abutment body under the effects of concrete shrinkage and various temperature changes are summarized, and influencing factors on the abutment are analyzed, including the parameters of horizontal crack-control reinforcement, the pile rigidity, the difference in age of the pile cap and abutment backwall concrete, and the inclusion of a postcast strip in the abutment backwall. The following conclusions were obtained:

(1) The total strain crack model created using Midas/FEA can effectively analyze the cracking behavior of concrete with outstanding convergence, direct posttreatment, and output of critical data such as crack width.

(2) The major reason for the appearance of vertical cracks in an abutment is that, under the joint effect of concrete shrinkage and temperature change, deformation appears between the pile cap and the abutment backwall but is constrained by the stiffness of the piles so that cracks appear in the abutment backwall above the piles and develop vertically.

(3) The abutment backwall should be provided with reinforcement according to the design load requirements. Holding the reinforcement ratio for a horizontal crack-control reinforcement constant, a "thin but dense" arrangement is more favorable for controlling the growth of vertical cracks on the abutment backwall.

(4) While meeting the basic design load requirements, the diameter (and concomitant stiffness) of abutmentsupporting piles should be reduced, if possible, to alleviate the constraining effect of the piles on the deformation of the abutment backwall under concrete shrinkage and temperature change.

(5) The inclusion of a postcast strip in the construction of the abutment helps to release the deformation constraint on the abutment backwall and thus greatly reduces the width of cracks.

(6) The normal stress on the abutment backwall caused by the difference in age of the pile cap and abutment backwall concrete is far lower than the tensile 
strength of the concrete, thus, the contribution of the concrete age difference can be safely ignored.

\section{Conflicts of Interest}

The authors declare that they have no conflicts of interest regarding the publication of this article.

\section{Acknowledgments}

The authors wish to acknowledge the financial supports from the project of the Basic Research Project for Universities of Liaoning Province (Grant no. LJZ2017043), Postdoctoral Innovation Fund Project of Shenyang Jianzhu University (Grant no. SJZUBSH201712), and Open Fund of MOE Key Lab of Disaster Forecast and Control in Engineering of Jinan University (Grant no. 20160626004).

\section{References}

[1] S. Munuswamy, Creep and Shrinkage Effects on Integral Abutment Bridges, ProQuest Dissertations and Theses Global, Ph.D. thesis, Florida Atlantic University, Boca Raton, Florida, 2004.

[2] C. Wang and Z. Zhou, "Model experimental study of failure mechanism and countermeasures of u-shaped high abutment with masonry-stones," Chinese Journal of Rock Mechanics \& Engineering, vol. 27, pp. 2727-2732, 2008.

[3] S. N. Shoukry, G. W. William, and M. Y. Riad, "Response of an integral abutment bridge to temperature variations," in Proceedings of Structures Congress 2008: Crossing the Borders, Vancouver, BC, Canada, April 2008.

[4] Y.-N. Yu, W. Zhang, and Y.-G. Shen, "Control measures for preventing crack on the surface of mass concrete abutment in early stage," Journal of Zhejiang University, vol. 8, p. 40, 2010.

[5] K. Flaga, B. Klemczak, and A. Knoppik-Wróbel, "Early-age thermal-shrinkage crack formation in bridge abutmentsexperiences and modelling," in Proceedings of "fib" Symposium Tel-Aviv Engineering a Concrete Future: Technology, Modelling \& Construction, vol. 4, Tel Aviv, Israel, April 2013.

[6] F. Barsoum, A. El Safty, and L. Phillip, "using finite element analysis to evaluate the performance of cracked bridge decks," in Proceedings of Structures Congress 2012, Chicago, IL, USA, March 2012.

[7] J. Chen, J. Deng, J. Wei, X. Wu, and A. Zhang, "Cause analysis of cracking in right abutment slope of Changheba hydropower station," Chinese Journal of Rock Mechanics and Engineering, vol. 6, p. 6, 2012.

[8] K. V. L. Subramaniam, "Identification of early-age cracking in concrete bridge decks," Journal of Performance of Constructed Facilities, vol. 30, no. 6, 2016.

[9] Y. Xia, H. Nassif, and D. Su, "Early-age cracking in high performance concrete decks of a curved steel girder bridge," Journal of Aerospace Engineering, vol. 30, no. 2, 2016.

[10] R. Akbari, "Crack survey in unreinforced concrete or masonry abutments in short- and medium-span bridges," Journal of Performance of Constructed Facilities, vol. 27, no. 2, 2013.

[11] L. E. Rodriguez, P. J. Barr, and M. W. Halling, "Temperature effects on a box-girder integral-abutment bridge," Journal of Performance of Constructed Facilities, vol. 28, no. 3, pp. 583-591, 2013.
[12] Japan Society of Civil Engineers, Standard Specifications for Concrete Structures, JSCE-SSCS, Japan Society of Civil Engineers, Tokyo, Japan, 2002.

[13] Ministry of Transport of the People's Republic of China, Code for Design of Highway Reinforced Concrete and Prestressed Concrete Bridge and Culverts, JTGD62-2012, China Communications Press, BeiJing, China, 2012. 


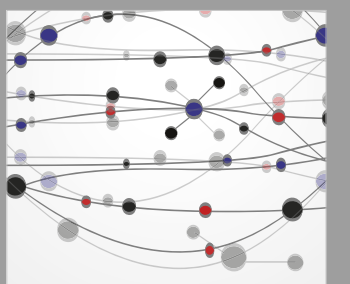

The Scientific World Journal
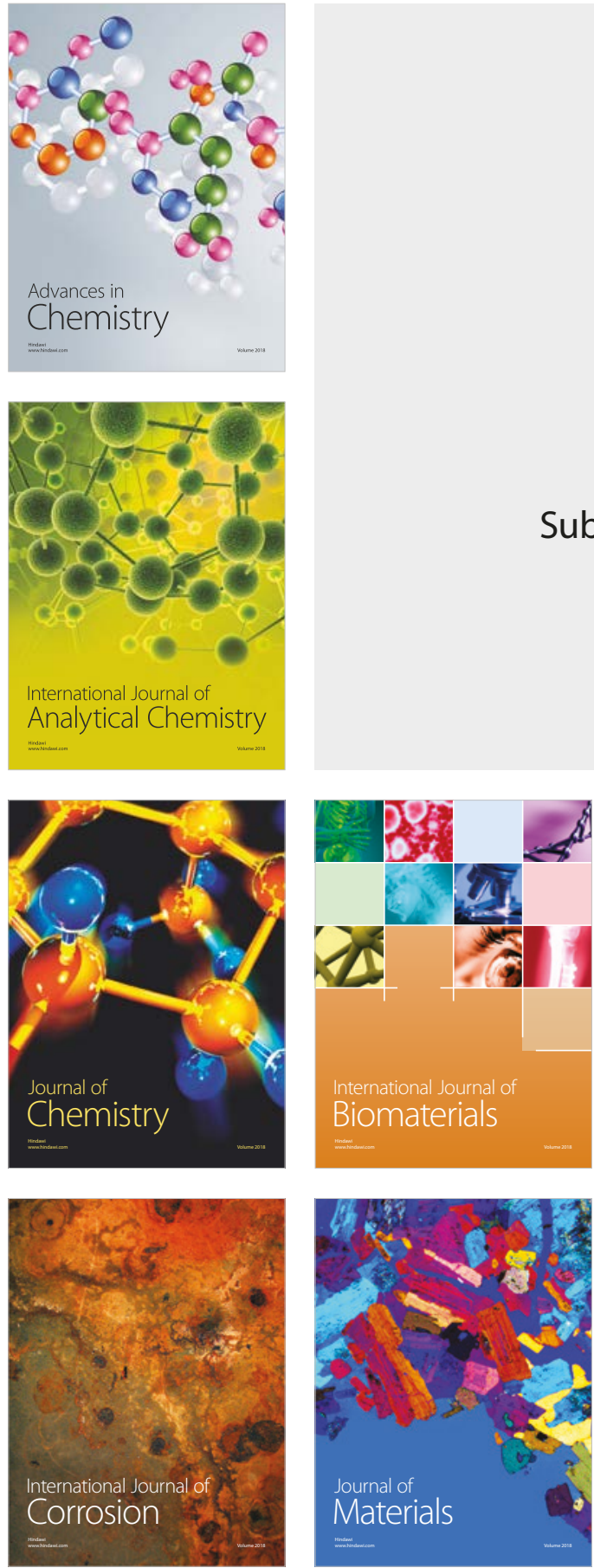

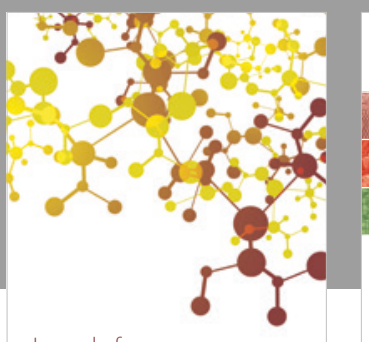

Journal of

Applied Chemistry
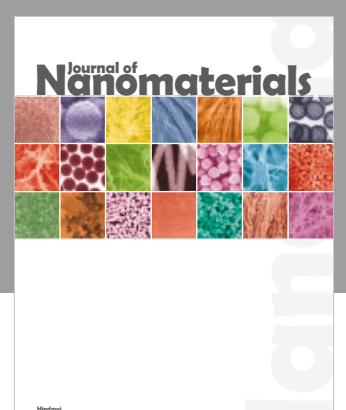

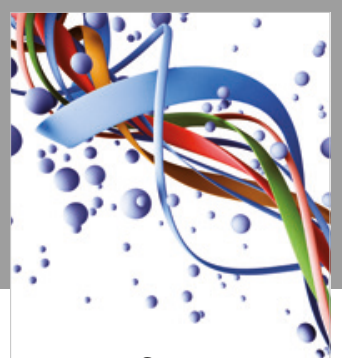

Scientifica

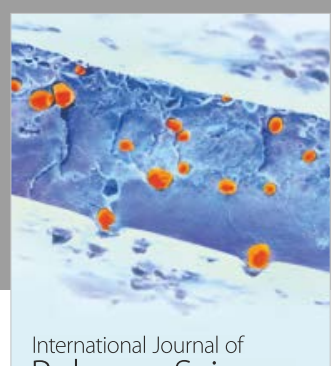

Polymer Science

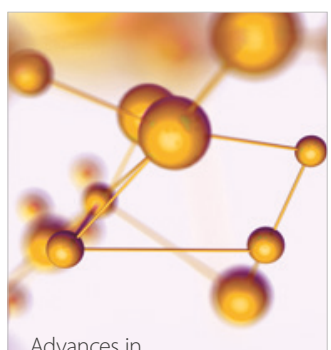

Physical Chemistry
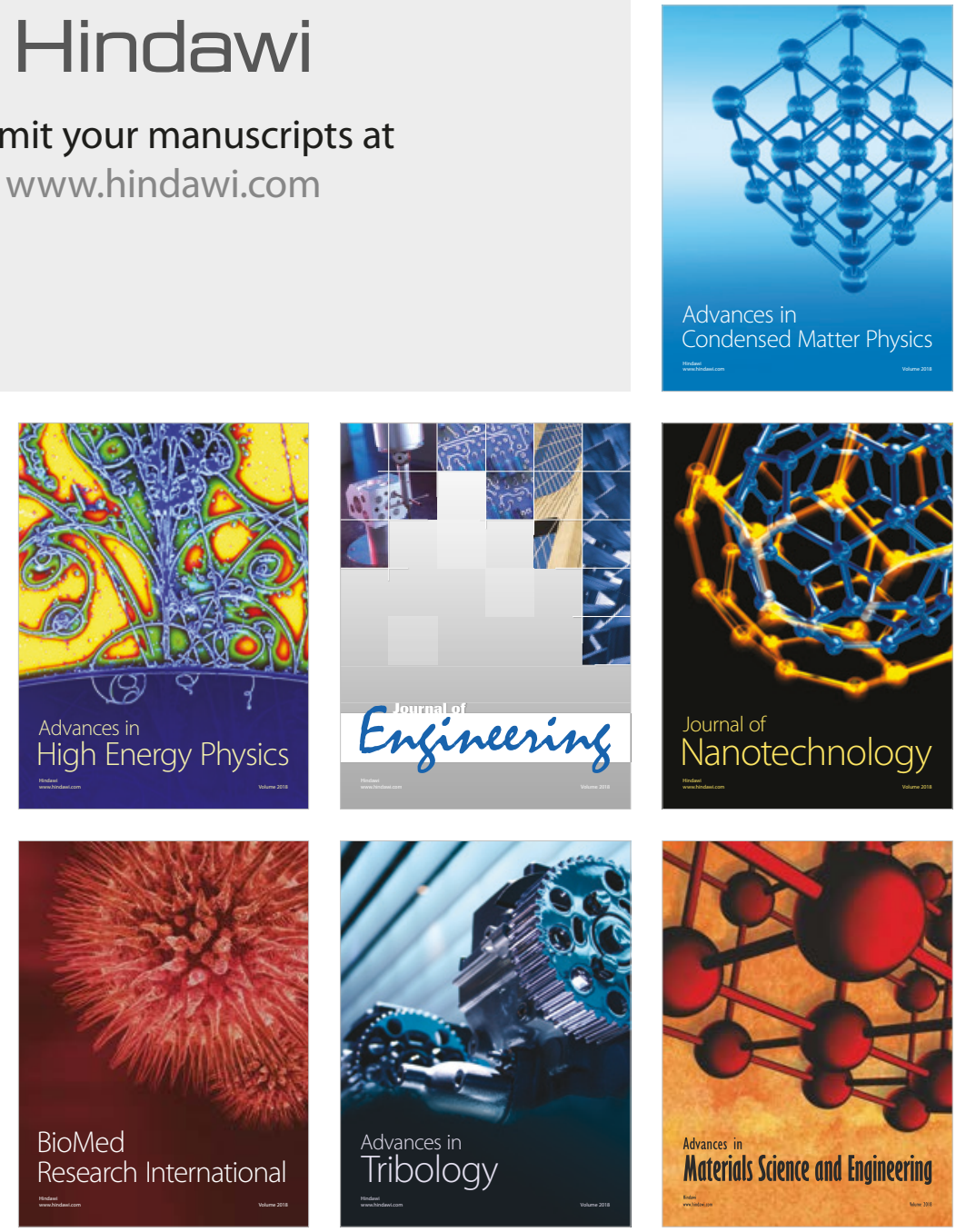